IA GEOMORPHOLOGICA
WWW.ugb.org.br

\title{
UMA PROPOSTA DE COMPARTIMENTAÇÃO GEOMORFOLÓGICA PARA A REGIÃO DE CÁSSIA, SUDOESTE DO ESTADO DE MINAS GERAIS
}

\author{
Samia de Moura Passarella \\ Universidade Estadual Paulista "Julio de Mesquita Filho", Departamento de Petrografia e Metalogenia - \\ CEP 13506-000 - Rio Claro,SP - e-mail: passarellasm@gmail.com
}

Norberto Morales

Universidade Estadual Paulista “Julio de Mesquita Filho”, Departamento de Petrografia e Metalogenia CEP 13506-000 - Rio Claro,SP - e-mail: nmorales@rc.unesp.br

José Eduardo Sartori

Universidade Estadual Paulista “Julio de Mesquita Filho”, Departamento de Petrografia e Metalogenia CEP 13506-000 - Rio Claro,SP - e-mail:sartori@rc.unesp.br

\begin{abstract}
Resumo
A região de Cássia, no sudoeste do estado de Minas Gerais encontra-se fortemente afetada por processos intensos de denudação associados ao soerguimento, deposição de sedimentos em bacias marginais e formação de bacias continentais. Os atributos que a tornam interessante para este trabalho seriam relacionados à diversidade de sua constituição geológica e geomorfológica que abrange tanto aos terrenos cristalinos pré-cambrianos quanto as rochas e sedimentos da borda leste da Bacia Sedimentar do Paraná. Estas rochas estão configuradas em um quadro evolutivo de embasamento pré-cambriano, com desenvolvimento de grande bacia de sedimentação, com diferentes ciclos desde o Permiano até o final do Cretáceo, que podem ser notados pela presença de relevo residual com testemunhos da superfície de aplainamento, a partir da qual se instalou o sistema de drenagem atual, com a influência de processos exógenos e endógenos. Portanto neste trabalho foi possível caracterizar três diferentes tipos de compartimentos geomorfológicos determinados através da compartimentação das unidades de relevo que busca realçar feições de relevo, padrões e anomalias de drenagens através da relação com suas estruturas do substrato rochoso, sendo eles: Compartimento "Planaltos Residuais Cuestiformes", "Patamares da Canastra" e "Planalto de Varginha".
\end{abstract}

Palavras-chave: Compartimentação geomorfológica, região de Cássia e geomorfologia estrutural.

\begin{abstract}
The region of Cássia, southwestern of Minas Gerais is being strongly affected by intensive denudation associated with the uplifting processes, deposition of sediments in marginal basins and continental basins formation. The attributes which make it interesting for this work would be related to the diversity of geomorphological and geological constitution covering both Precambrian crystalline terrain and the rocks and sediments on the eastern edge of the Paraná Sedimentary Basin. These rocks are configured in an evolutionary framework of Precambrian basement, with the development of large sedimentation basin and different cycles from the Permian to the end of the Cretaceous. It may be noticed by the presence of residual relief with vestiges of the planning surface, in which it was installed the current drainage system with the influence of exogenous and endogenous processes. Therefore, the aim of this work is the characterization of
\end{abstract}


the three different types of geomorphologic compartments determined by the subdivision of relevant units which seeks to highlight the relief features, drainage patterns and anomalies through the relation with its structures of the rocky substrate, being: Compartiment "Planaltos Residuais Cuestiformes", "Patamares da Canastra" e "Planalto de Varginha".

Keywords: Geomorphological compartimentation, region of Cássia and structural geomorphology.

\section{Introdução}

A Geomorfologia tem como propósito analisar as formas de relevo, buscando compreender as relações processuais pretéritas e atuais (CASSETI, 1994), e por isso torna-se uma ciência valiosa para a aquisição do conhecimento do meio físico e da constituição da paisagem. Uma quantidade considerável de trabalhos buscam contribuir cada vez mais sobre a importância dos processos tectônicos na formação das paisagens atuais que são investigados através da relação do modelado superficial com as estruturas rochosas (SUMMERFIELD, 1991; SAADI, 1990, 1991, 1993; STEWART \& HANCOK, 1994; GONTIJO, 1999; BURBANK \& ANDERSON, 2001; BURKE \& GUNNELL, 2008).

O Brasil é um país que ilustra muito bem os estudos a respeito das paisagens de relevo relacionados a zonas intraplacas, pois apenas considerando suas proporções continentais nota-se que ele oferece uma gama diversificada de sistemas de relevo e paisagens que merecem este tipo de investigação.

Um exemplo seria sua região sudeste, que é caracterizada pela presença e riqueza de relevos residuais com testemunhos de superfícies erosivas, a partir das quais foram instalados o sistema de drenagem atual, com a influência tanto de processos endógenos quanto de processos exógenos. Essa região possui também uma variação de substrato rochoso ora representado por rochas metamórficas précambrianas, ora por rochas Fanerozóicas, referentes à Bacia Sedimentar do Paraná (FIORI, 1977; WERNICK, ET AL., 1979; OLIVEIRA et al. 1983; PIRES, 2001; MORALES, 1993; SIMÕES, 1995; VALERIANO et al., 2004; CASTRO 2004).

Portanto a proposta deste trabalho é mostrar os principais traços geomorfológicos da região estudada assim buscando reconhecer os acidentes geomorfológicos, os padrões e elementos de relevo e de drenagem, e por fim associá-los aos conjuntos litológicos presentes elaborando através destes uma compartimentação geomorfológica para a região de Cássia (MG).

\section{Área de Estudo}

A área investigada abrange a região de Cássia e São Sebastião do Paraíso, no sudoeste do estado de Minas Ge- rais, situada entre os paralelos $20^{\circ} 30^{\prime}$ a $21^{\circ} 00^{\prime}$ de latitude Sul e os meridianos de $47^{\circ} 00^{\prime}$ a $46^{\circ} 45^{\prime}$ de longitude Oeste (Figura 1).

Essa região é constituída por terrenos cristalinos adjacentes à Bacia do Paraná, apresentando um quadro evolutivo de embasamento pré-cambriano, com desenvolvimento de grande bacia de sedimentação, com diferentes ciclos desde o Permiano até o final do Cretáceo. Este quadro é representado pelas rochas magmáticas e metamórficas do Cráton do São Francisco a leste, bordejado pelas rochas metamórficas da Faixa Brasília, representada na área pelos grupos Araxá e Canastra, com quartzitos, xistos e gnaisses diversos. Na região, a Bacia do Paraná é representada pelos sedimentos do Grupo Itararé, das formações Pirambóia e Botucatu e pelos magmatitos da Formação Serra Geral.

No quadro evolutivo regional, é destacada a importância da atuação do Soerguimento do Alto Paranaíba, reativando a borda da bacia na região, promovendo a formação dos sedimentos neocretácicos correlatos ao Grupo Bauru e até mesmo a existência de sedimentos mais jovens.

Posteriormente a região foi submetida a longo período de estabilidade tectônica, tendo permitido o desenvolvimento de extensa superfície erosiva aplainada que recobre os altos da Serra da Canastra na margem direita do Rio Grande, mas também com inúmeros testemunhos de relevo residual, na forma de mesas, piões, ou planalto descontínuo, presentes na margem esquerda deste mesmo rio. Esta superfície de aplainamento é conhecida como a Superfície Sul-Americana (KING, 1956), sendo caracterizada pelo desenvolvimento de espesso perfil de alteração com presença de crostas endurecidas lateríticas ferruginosas.

\section{Metodologia}

Este trabalho foi desenvolvido de modo interdisciplinar, o que possibilitou o uso tanto de técnicas e procedimentos ligados aos estudos da geomorfologia quanto da geologia estrutural e tectônica.

Para a confecção do material cartográfico foram utilizadas as cartas topográficas na escala 1:50.000 do Instituto Brasileiro de Geografia e Estatística (IBGE) dos municípios de: Cássia (Folha SF 23 V A VI 1) e São Sebastião do Paraíso (Folha SF 23 V A VI 3). 


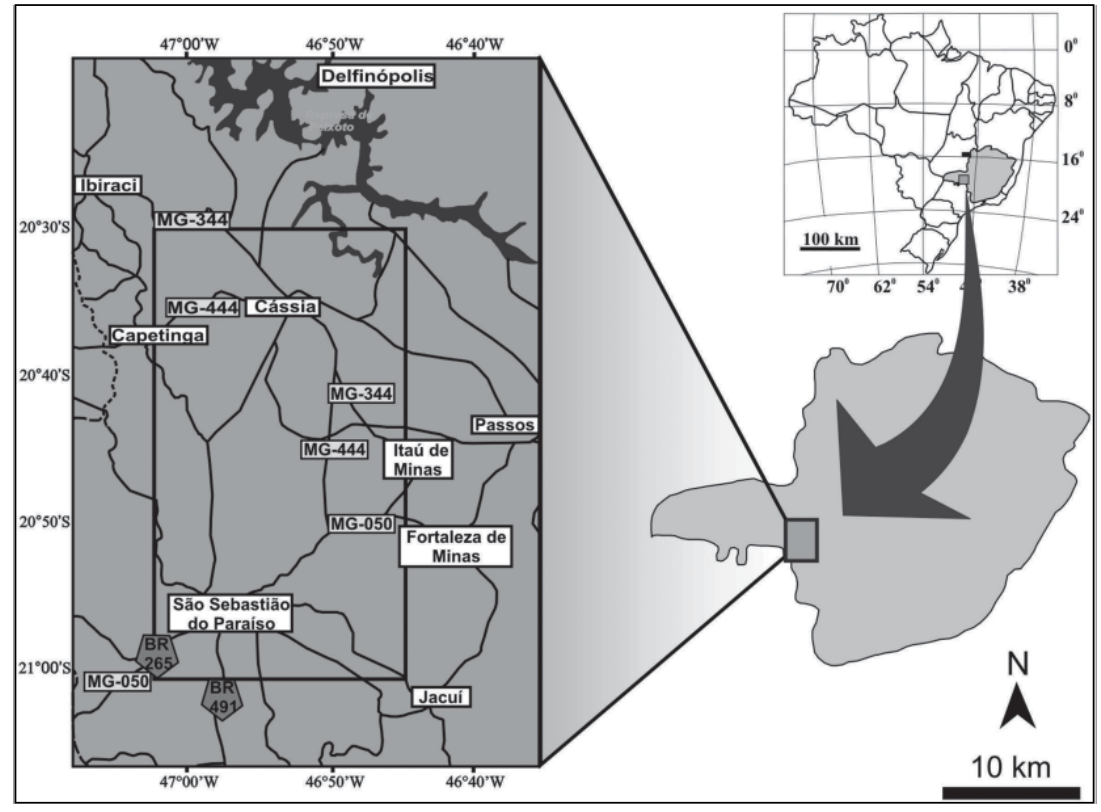

Figura 1 - Mapa esquemático de localização da área de estudo, com indicação dos núcleos urbanos e das rodovias de acesso. (Fonte: Base cartográfica de mapas de rodovias GOOGLE 2007).

Posteriormente foi feito um trabalho de fotointerpretação que complementou informações a respeito dos principais traços de relevo e drenagem obtidos através das fotografias áreas na escala de 1:60.000. Esses produtos foram integrados no ambiente do software ARC.GIS-9.3, serviram de base para a análise de relevo e da rede de drenagem.

Essa análise foi elaborada considerando variáveis como a distribuição dos principais conjuntos de rochas apresentadas no mapa geológico compilado de Oliveira et al. (1983), a caracterização dos diferentes padrões de drenagem a partir dos conceitos estabelecidos por Bishop (1995) e por fim a identificação das principais feições e padrão do relevo da área por Soares e Fiori (1976). Permitindo assim uma análise macroscópica de reconhecimento do padrão do relevo e do maciço rochoso, com vistas à investigação de prováveis controles estruturais na preservação de depósitos superficiais, e possíveis indicadores de atividades neotectônicas.

Para um melhor entendimento dos dados estruturais, foram extraídos 1.688 seguimentos retilíneos da rede de drenagem através do software ARC.GIS-9.3, e que posteriormente foram importadas para o software AUTOCAD, para gerar os diagramas de roseta através da rotina roseta.lisp., e também foram trabalhadas medidas de fraturas compiladas de Oliveira et al. (1983) no software STEREONET, que proporcionaram gráficos que atenderam o propósito de melhor observar os principais conjuntos de orientações, e proporcionar através destes uma analise quantitativa e qualitativa dos principais elementos tectônicos da área.

O Modelo Digital do Terreno foi gerado no software ARC.GIS-9.3 e teve como propósito para este trabalho a identificação das principais feições e padrões do relevo da área, bem como a caracterização de compartimentação local.

Por fim, o cruzamento destes dados juntamente com informações obtidas em campo consistiu na elaboração do mapa de feições de relevo $e$ de compartimentação geomorfológica, que com base nas distribuições de feições de relevo associadas ao modelo de elevação e ao quadro da rede de drenagem, proporcionou e ajudou no entendimento da evolução geomorfológica regional.

\section{Resultados e discussão}

Os principais elementos que caracterizaram a compartimentação geomorfológica da área estudada foram à análise do relevo, da configuração da rede de drenagem e do reconhecimento das principais anomalias, enfatizados através do estudo e entendimento de padrões de relevo e anomalias de drenagens em conjunto com o reconhecimento das posições espaciais das estruturas das rochas, das falhas e fraturas e, ainda, de acordo com as direções de mergulho de camadas, que ofereceram diversos padrões de simetria ou assimetria. 


\section{a) Análise do relevo}

Para melhor visualizar o quadro geomorfológico da área estudada foi utilizado o Modelo Digital do Terreno (Figura 2), montado com base nas imagens SRTM disponibilizadas pela NASA. Neste modelado de relevo juntamente com as fotografias aéreas foi possível realizar um estudo padronizado das feições de relevo, com padrões de amplitude, declividade, formas de topo, drenagem, vales e vertentes, ajustados aos traços estruturais dos conjuntos litológicos presentes na área que permitiram a definição e delimitação dos três compartimentos para a região estudada (Figuras 2 e 3), sendo eles: 1-Compartimento dos "Planaltos Residuais Cuestiformes", 2-Compartimento dos "Patamares da Canastra" e 3-Compartimento do "Planalto Varginha".

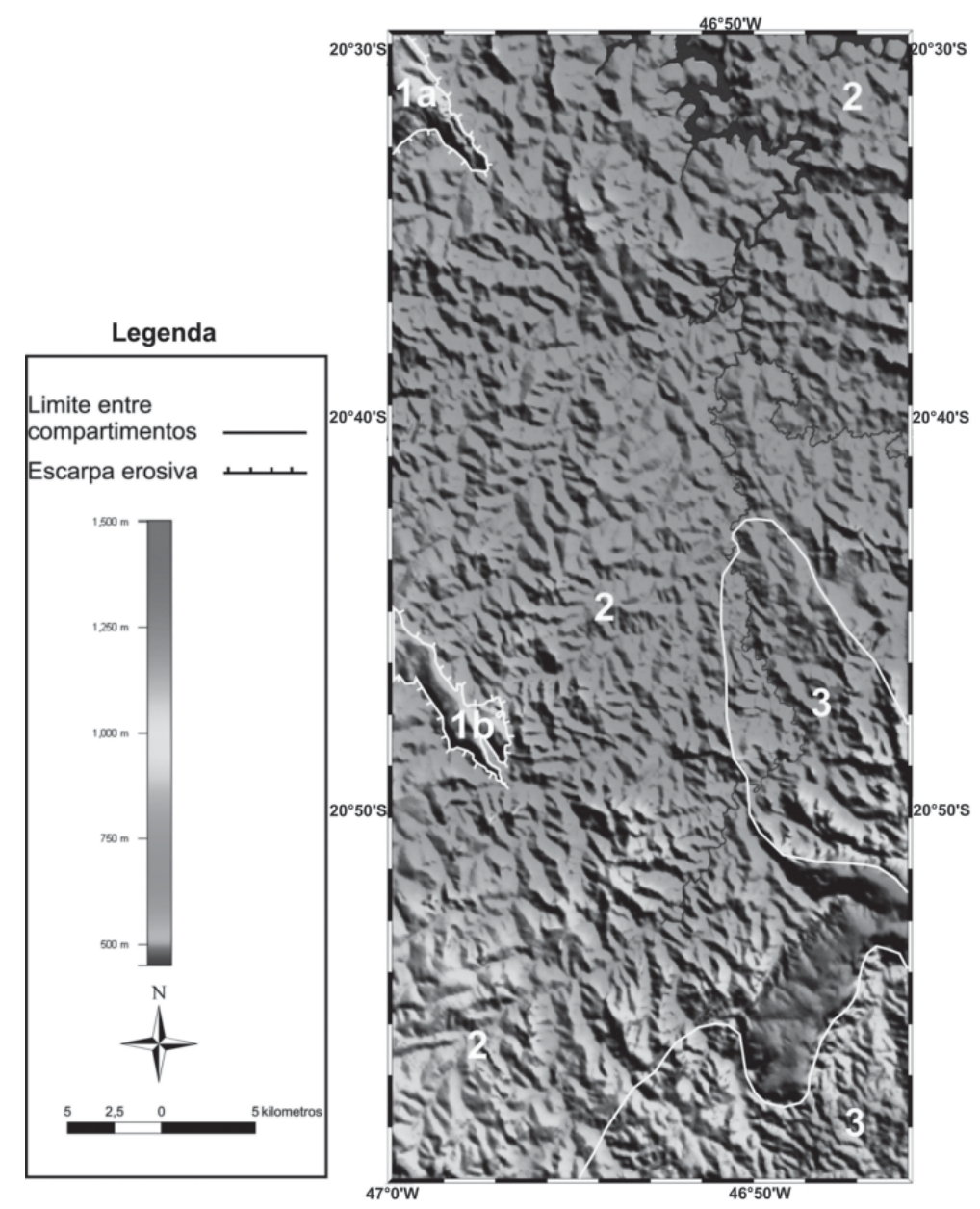

Figura 2 - Modelo Digital do Terreno montado com bases nas imagens SRTM, com indicação da hipsometria e compartimentação geomorfológica da área de estudo.

\section{b) Análise da configuração da rede de drenagem}

O estabelecimento da rede de drenagem da área foi interpretado e associado ao rompimento de superfícies aplainadas que, ao dissecá-las, se instalou aproveitando as estruturas do embasamento pré-cambriano para desenvolver formas mais resistentes de relevo, tendo passado nessa dissecação pela resistência de rochas basálticas e de rochas sedimentares silicificadas.
Três padrões principais podem ser reconhecidos na área de estudo; são eles: os dendríticos, subdendríticos e treliça, (Figura 4). Estes padrões são ajustados fortemente aos traços estruturais dos conjuntos litológicos presentes, exibindo diversos tipos de anomalias com formas de cotovelo ou candelabro (Figura 5). 


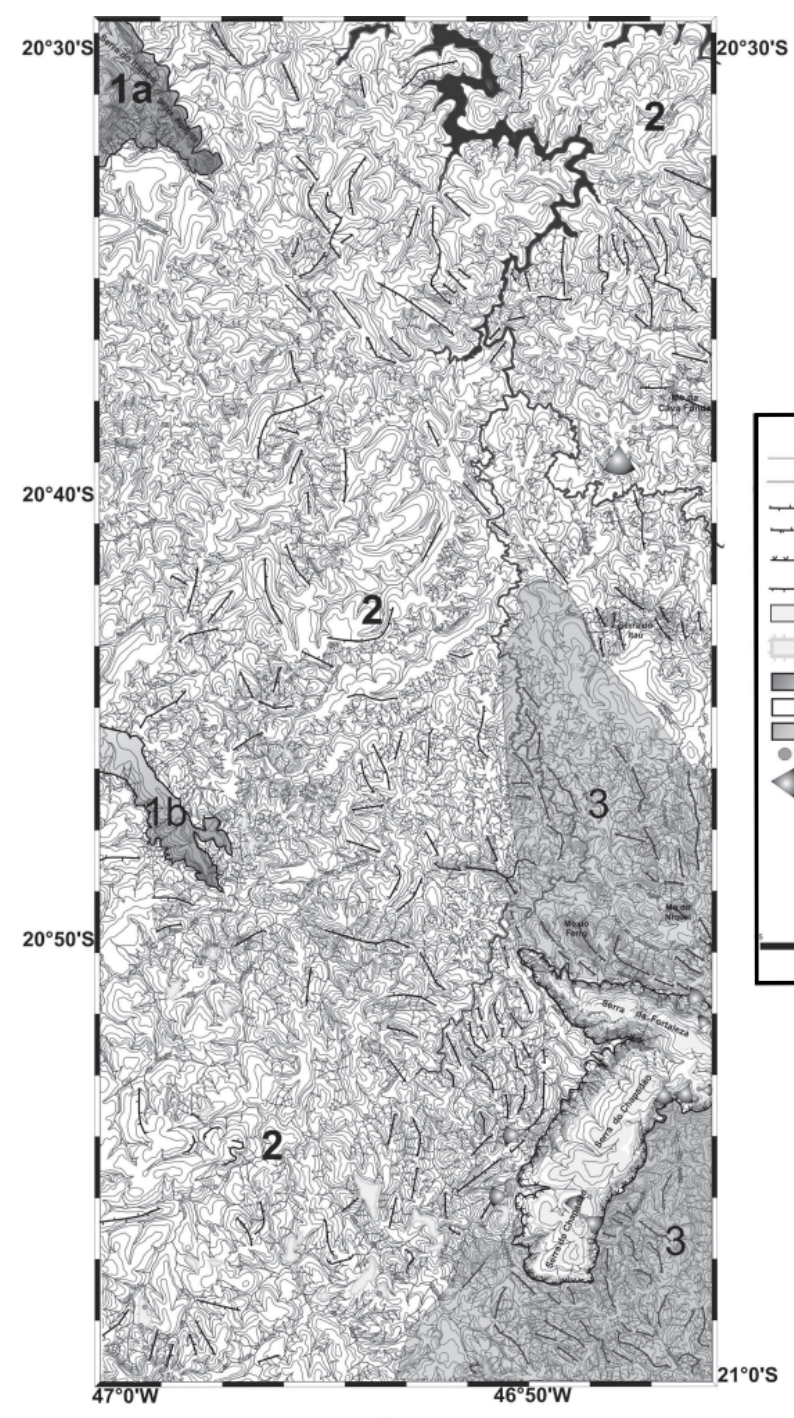

Figura 4 - Mapa da rede de drenagem destacando pelas cores seus respectivos padrões de drenagem.

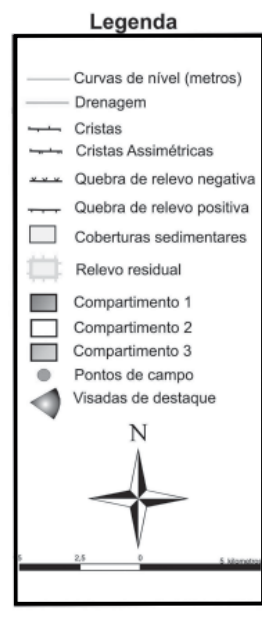

Figura 3 - Mapa de compartimentos com indicação e destaque das principais feições de relevo analisadas neste estudo.

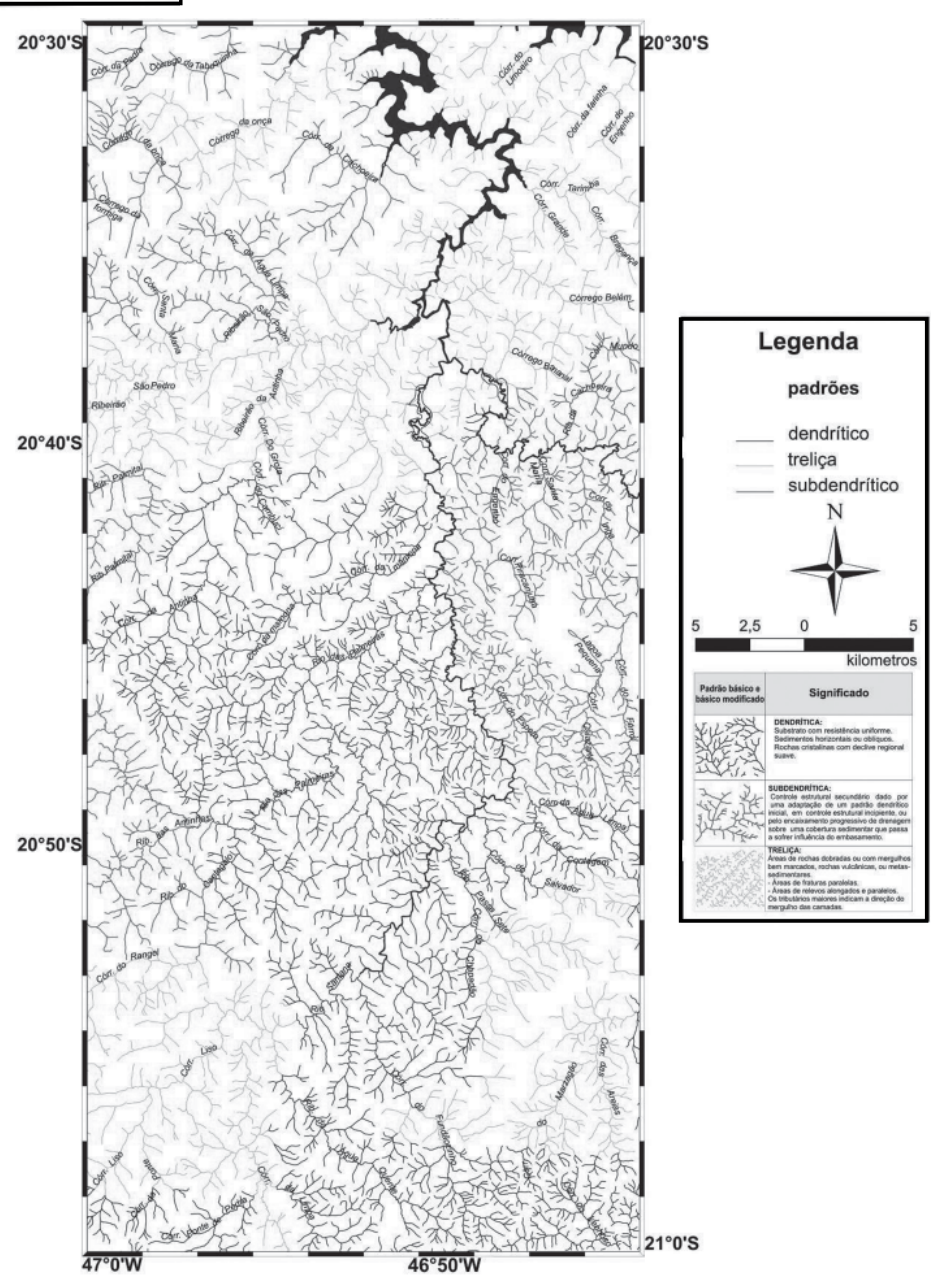




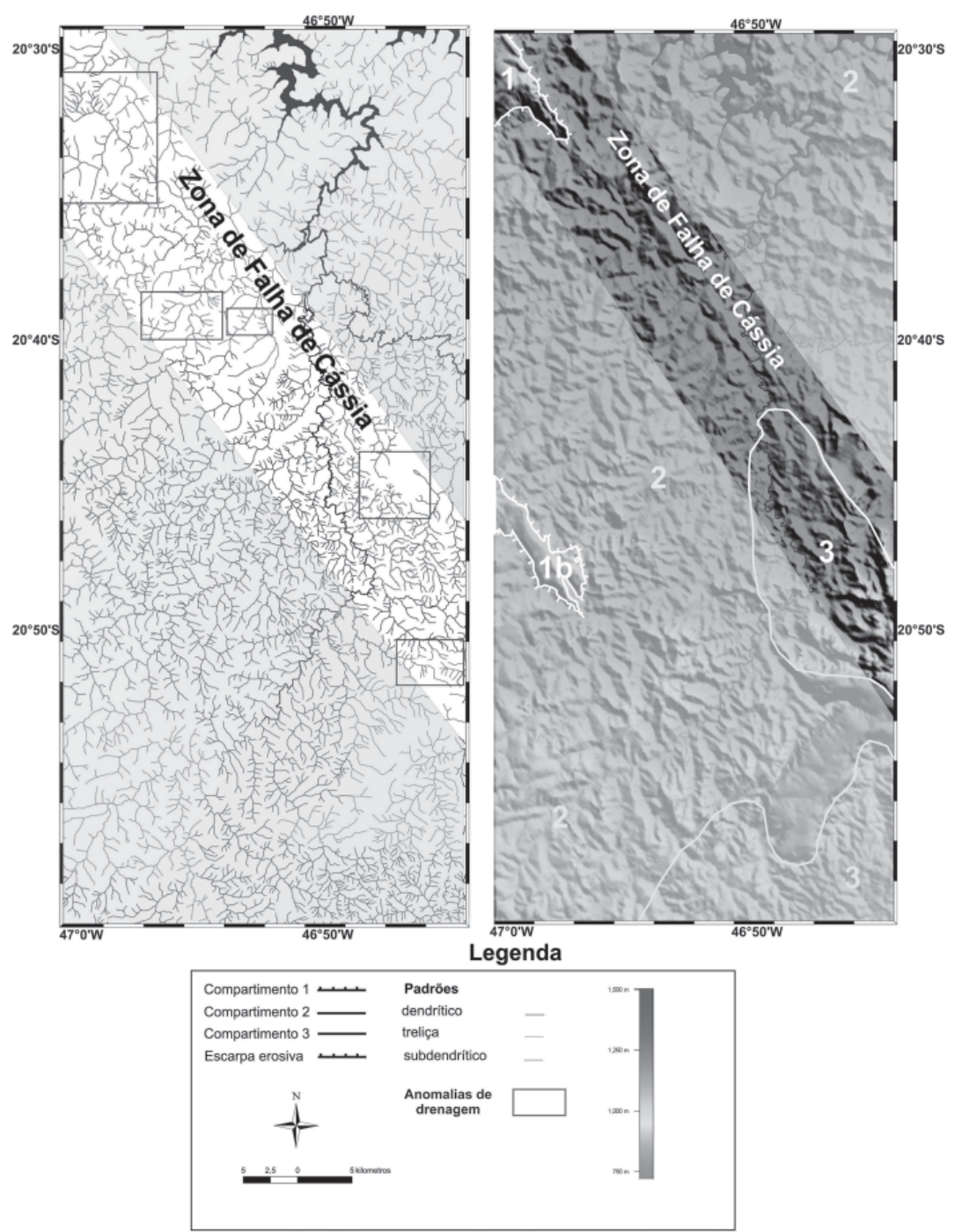

Figura 5 - MDT referente à Zona de Falha de Cássia e Padrões de drenagem associados a mesma, evidenciando anomalias.

c) Análise de lineamentos de drenagem e medidas

\section{de fraturas}

A partir da análise das cartas de drenagem da área, foram extraídos 1.688 lineamentos, ou seja, segmentos retilíneos dos traços de drenagem (Figura 6), que trabalhados no software AUTOCAD deram origem a diagramas de roseta.

Essas rosetas revelaram que as direções principais podem ser consideradas NW-SE, e subordinadamente NESW, N-S e E-W Figura 6. Ao interpretá-las separadamente, percebeu-se que a direção preferencial NW-SE pode ser associada aos traços da Zona de Falha de Cássia (Figura 5) e que as outras direções podem ser associadas aos efeitos de ajuste ao padrão de fraturamento das rochas no quadro regional.

Compilados de (OLIVEIRA et al., 1983) foi realizado a integração e tratamento dos dados estruturais obtidos de
1004 medidas de fraturas que levaram a preparação dos stereogramas da Figura 6.

Ao analisar estes stereogramas foi constatado um padrão de distribuição em guirlanda, com forte predomínio de fraturas verticais a subverticais, com três direções principais, ou famílias de juntas: N25E/90, N72E/90 e N60W/90. Estas famílias apresentaram uma boa concordância com o tratamento do padrão de lineamentos.

A caracterização de feixes de lineamentos, como já apresentado para análise do relevo, é destaque para os traços da Zona de Falha de Cássia, formando os lineamentos de maior comprimento, os de melhor ajuste e maior quantidade, refletindo nas rosetas construídas e, como esperado, forte indicador desta zona de falha. 


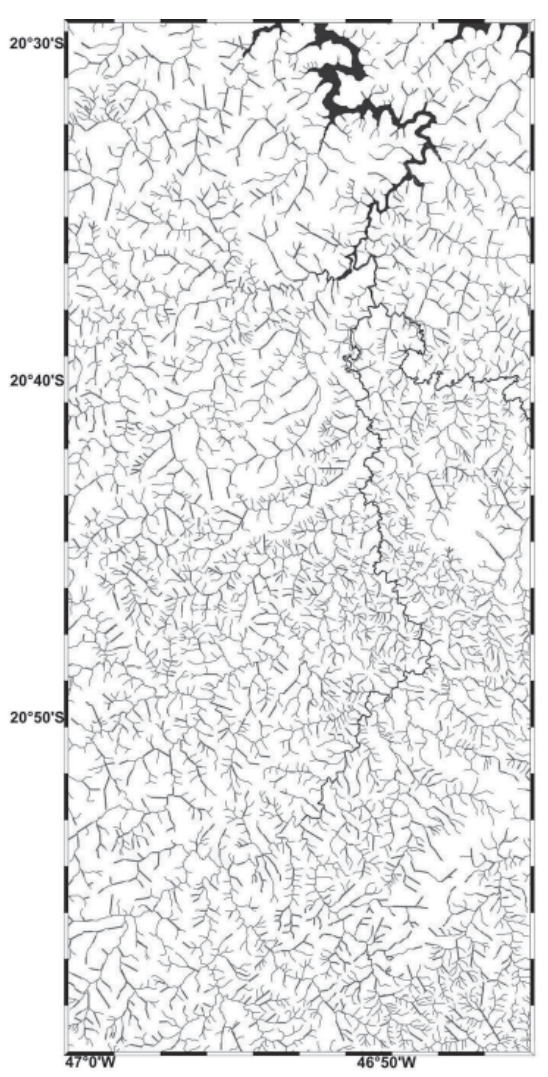

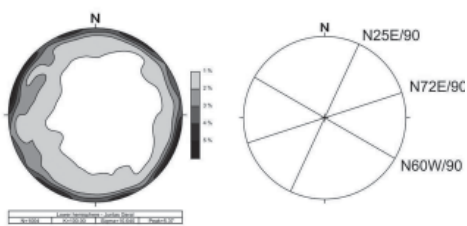
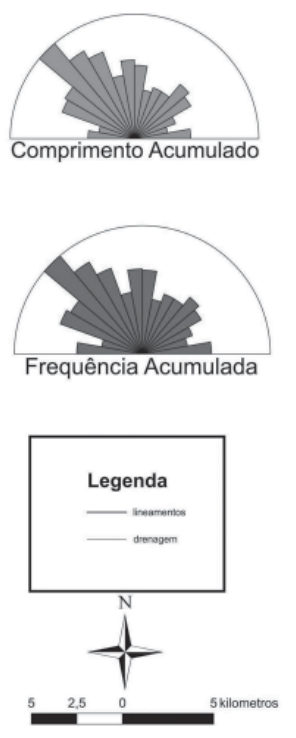

Figura 6 - Mapa de lineamentos traçados sobre a rede de drenagem, com a presença de seus respectivos diagramas de roseta referentes ao comprimento e frequência acumulados dos lineamentos, com intervalo de 10 graus, e e referentes às medidas de fraturas (das cartas de Cássia e São Sebastião do Paraíso) extraídas do mapeamento geológico e estrutural do Projeto Cássia (Oliveira et al., 1983).
A seguir estão separadamente com maiores detalhes os citados compartimentos geomorfológicos:

\section{Compartimento-1 "Planaltos Residuais Cuestiformes"}

Este relevo é fortemente assimétrico e está relacionado ao padrão sub-horizontal do acamamento presente nas rochas. Refletido em formas típicas de um relevo de estrutura concordante (PENTEADO, 1976; SOARES \& FIORI, 1976), como escarpas derivadas do Planalto de Franca e seus remanescentes testemunhos, mesas, peões e baús (Figura 7); ou como escarpas e morros testemunhos residuais de topos achatados sustentados pelo Grupo Itararé ou pela Formação Botucatu, ou ainda pelos diabásios do Sill Borda da Mata, correlatos da Formação Serra Geral, na passagem dos terrenos da Bacia do Paraná para os terrenos pré-cambrianos (Figura 8); ou ainda pelos restos de rochas sedimentares isolados em meio aos terrenos pré-cambrianos.

Este tipo de relevo forma feições do tipo quebras positivas e negativas (SOARES \& FIORI 1976) de pronto reconhecimento nas fotografias aéreas, com alto contraste entre os topos aplainados e horizontalizados e a escarpas íngremes até mesmo subverticais. Tanto são reconhecidas feições associadas a grandes desníveis que, caracteristicamente, marcam contatos entre unidades litoestratigráficas, como também são bem perceptíveis no terreno patamares com peque- nos desníveis, indicando alternância entre camadas ou variação de resistência à erosão entre elas.

Na porção NW da área, podem ser reconhecidos restos de crosta laterítica associados aos topos aplainados do Planalto de Franca, também reconhecidos por Perdoncini (2001) na região de Franca, se referindo à Superfície Sul-Americana, ou por Almeida (1974), se referindo ao Planalto Ocidental Paulista e à Superfície Japi.

\section{Compartimento-2 "Patamares da Canastra"}

Associado às camadas inclinadas, este compartimento resulta em padrões de relevo moderadamente a levemente assimétricos. Associam-se a cristas alinhadas de rochas quartzíticas ligeiramente assimétricas, que denunciam esta inclinação dos estratos, no caso marcados pela forma aproximadamente tabular das camadas (Figura 9) e, em nível de afloramento, pelo bandamento composicional (quartzo-mica) presente nas rochas.

Os quartzitos têm destaque por sua durabilidade diante dos processos erosivos, formando assim cristas alinhadas, como no caso do Antiforma de Itaú, ou mesmo serras imponentes, como no caso da Sinforma do Chapadão. Em ambos os casos, é possível reconhecer a inclinação dos estratos pela observação dos traços dos contatos entre as camadas nas encostas e vertentes, localmente formando estruturas do tipo "hogbacks" (Figura 10). 


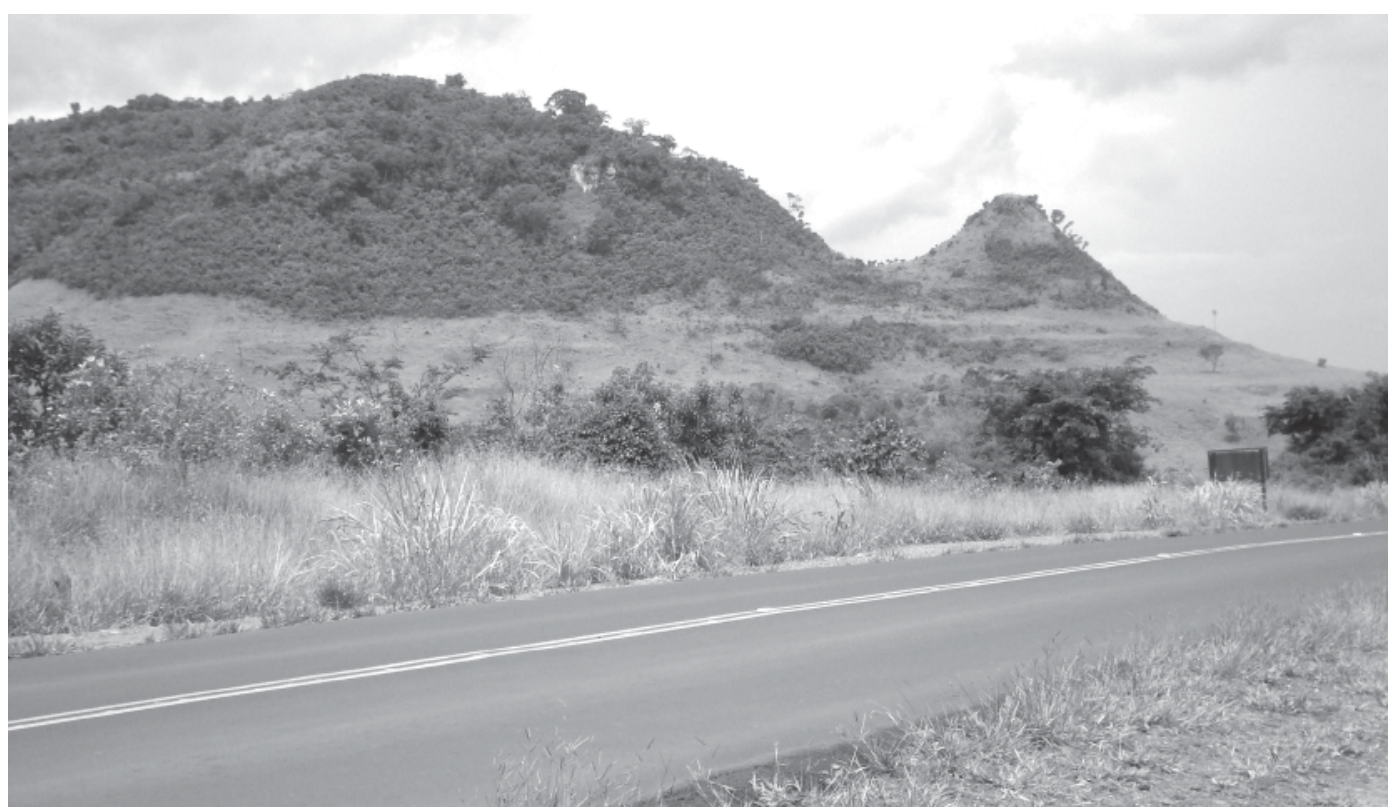

Figura 7 - Visada de SSW para NNE da escarpa e morro testemunho de topos achatados sustentados pelos basaltos da Formação Serra Geral e arenitos da Formação Botucatu, retratando o relevo residual do Planalto de Franca (Ponto 34).

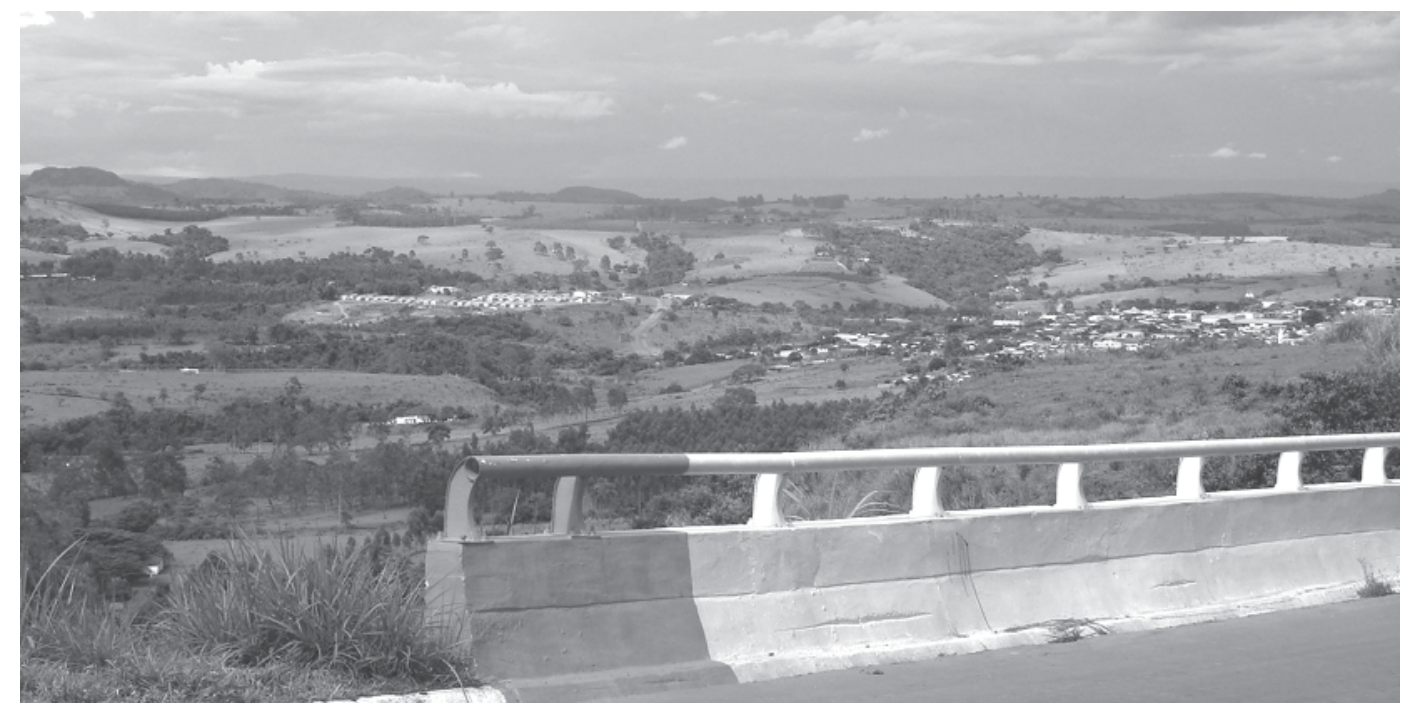

Figura 8 - Mesma visada da foto anterior, mostrando no primeiro plano afloramento de diabásios do Sill Borda da Mata (sustentando a escarpa), e os terrenos pré-cambrianos ao fundo (Ponto 36).

Este tipo de feição se refere à clássica forma triangular das vertentes. A observação destas feições triangulares permite o reconhecimento do mergulho ou inclinação das camadas (Figura 9) levando ao reconhecimento das grandes estruturas dobradas, da inclinação nas zonas periclinais e indicação do caimento dos eixos das grandes dobras.
O Sinformal do Chapadão e o Antiformal de Itaú são possíveis de se reconhecer e visualizar nas fotografias aéreas (Figuras 9 e 11) e no MDT da Figura 2. Estas formas possuem uma série de outras camadas de rochas resistentes que acompanham seus traços, como no caso do alinhamento de cristas sustentadas pelos quartzitos do compartimento-2, ou no caso alinhamento de cristas sustentadas por gnaisses do compartimento-3 ou "Planalto Varginha". 


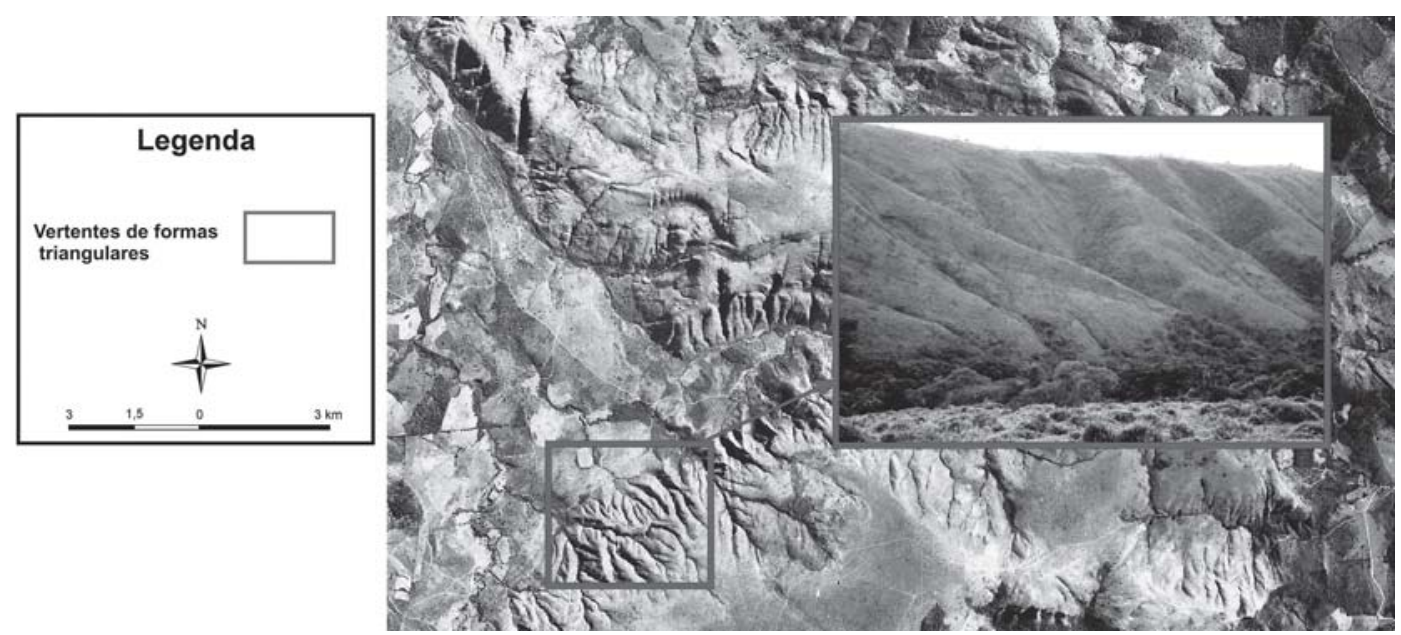

Figura 9 - Fotografia aérea da feição do Chapadão, com a intenção de destacar a forma triangular das suas vertentes.

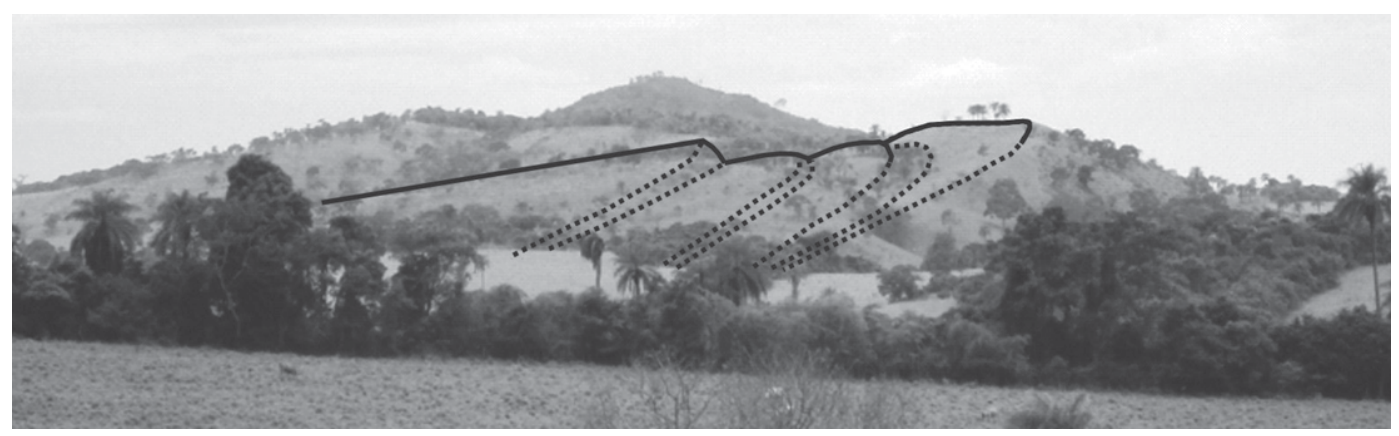

Figura 10 - Visada de W para E de relevo com pequena inclinação dos estratos conferido através da observação dos traços dos contatos entre as camadas nas encostas e vertentes, localmente formando estruturas que se assemelham aos hogbacks.

\section{Compartimento-3 "Planalto Varginha"}

Neste compartimento, as feições de destaque são sugeridas por cristas retilíneas e alinhadas associadas às rochas pré-cambrianas referentes aos complexos Varginha e Amparo.

As cristas alinhadas possuem vertentes íngremes de ambos os lados devido à inclinação verticalizada de suas camadas com topos com formatos de cúspide ou arredondados, caracterizando um modelado de relevo simétrico segundo a classificação de Soares e Fiori (1976). Tais características podem ser conferidas na porção norte da Serra da Fortaleza, fora do domínio da Sinforma do Chapadão (Figura 11).

\section{Atuação da "Zona de Falha de Cássia"}

De acordo com a análise dos dados estruturais de lineamentos de drenagem e medidas de fraturamentos, foi observado que as principais direções, conferidas nos diagramas de roseta e stereogramas (Figura 6), acusaram registros da atuação da Zona de Falha de Cássia, presente nos três compartimentos.
Cabe ressaltar que essa importante atuação tectônica desenha uma faixa que segue desde a porção NW da cidade de Cássia, balizando a Serra do Itambé, até as proximidades da parte N da Serra da Fortaleza, (Figura 5).

Onde na região referente ao compartimento-1 "Planaltos Residuais Cuestiformes" se percebe essa forte influência através do limite dos domínios de relevo referentes à Bacia do Paraná. A presença de feições como as Serra do Itambé (Figura 3) e do Agapito registram essa atuação tectônica através do alinhamento de cristas sustentadas por quartzitos e a mudança brusca dos padrões de relevo como passagem de planalto para patamares, reforçando ainda mais os limites dos compartimentos-1 e 2. Essas feições são marcadas por anomalias alongadas com direção preferencial NW-SE. Nos flancos das serras do Itambé e do Agapito, estas rochas mais resistentes formam anomalias de relevo na forma de cristas alinhadas que algumas vezes assemelham-se a facetas A análise do padrão de drenagem local permite o reconhecimento de anomalias, marcadas por zonas de confluência alinhadas e padrões tipo candelabro, podendo indicar um controle tectônico desta zona de falha no sistema de drenagem atual. Ao longo de toda a sua extensão, ocorrem registros das ativi- 
dades tectônicas, como as rochas de zonas de falhas representadas por cataclasitos, protocataclasitos e rochas brechadas (Figura 12). Nas proximidades do trevo de Cássia, ao longo da rodovia MG-344, a presença de sedimentos mais jovens deformados, brechados, falhados e ou pelíticos ricos em matéria orgânica (tipicamente lacustres) são indicadores de reativação desta zona de falhas, provavelmente relacionada a eventos neotectônicos que sugerem um possível barramento do sistema de drenagem pretérito trapezoidais, feições topográficas normalmente associadas a relevo de falhas.

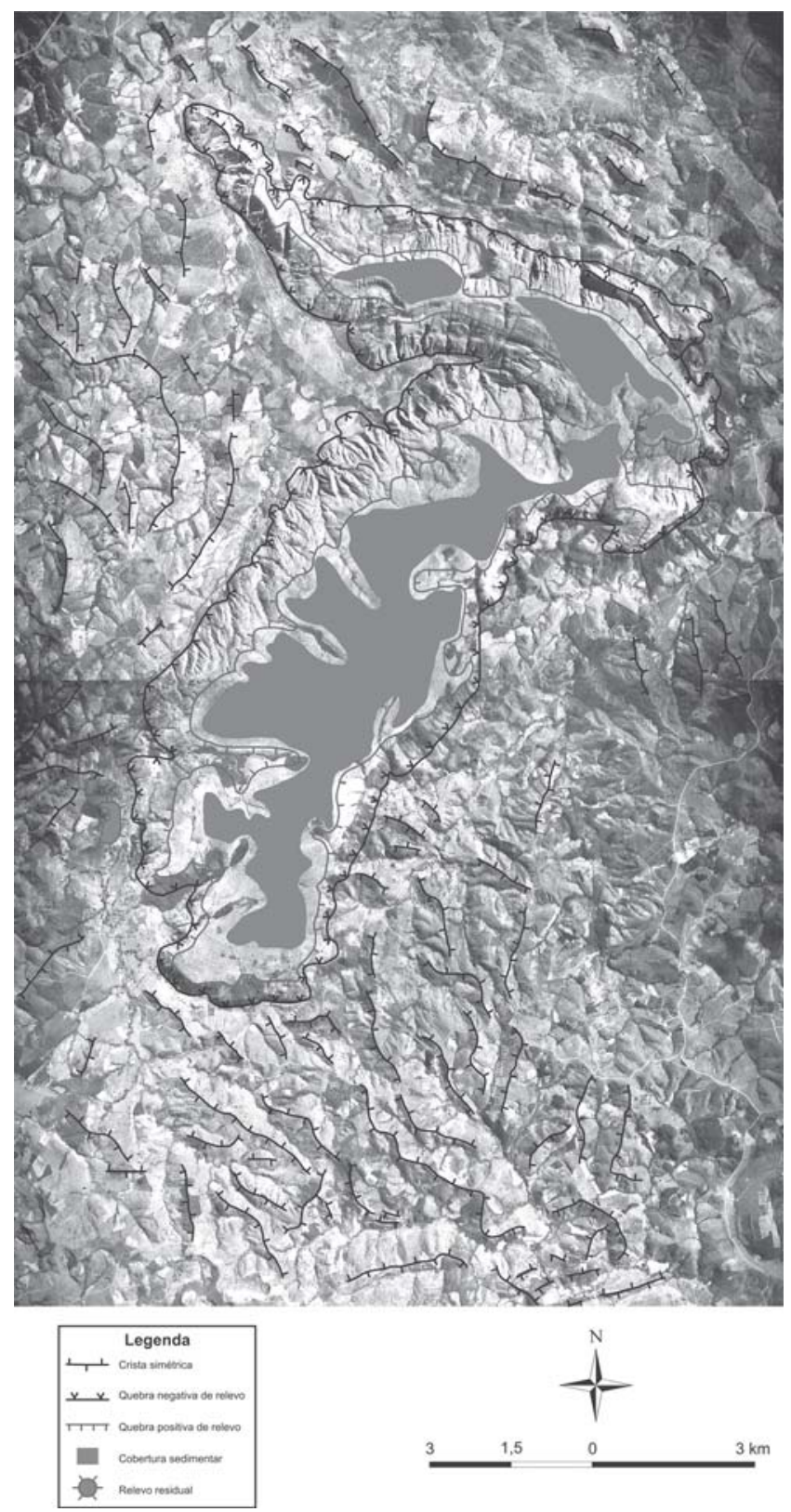

Figura 11 - Fotografia aérea ressaltando a Serra do Chapadão e as feições de destaque geomorfológico.
No caso do compartimento-2 "Patamares da Canastra" a atividade da Zona de Falha de Cássia influenciou a orientação do relevo ao longo da direção NW, causando forte alinhamento dos traços retilíneos de drenagens, cristas e morrotes (Figura 5 e 3 ).

Para o conjunto de relevo referente ao compartimento3 "Planalto Varginha" a influência que a Zona de Falha de Cássia trouxe foi conjunta com a disposição de litologias verticalizadas que colaboraram com a formação de diversos lineamentos de relevo com litologias resistentes de alto ângulo de mergulho, formando um padrão simétrico com direção NW-SE.

\section{Conclusão}

$\mathrm{Na}$ área investigada foi possível caracterizar três diferentes tipos de compartimentos geomorfológicos. Esses compartimentos foram determinados através do realce e análise de feições de relevo, padrões e anomalias de drenagens, que são típicas de diferentes estruturas do substrato rochoso.

No compartimento-1 "Planaltos Residuais Cuestiformes" as feições ostentam um padrão de acamamento que varia de sub-horizontal a horizontal e por isso passam a refletir um relevo fortemente assimétrico, marcado pela homogeneidade de feições escarpadas e alinhadas que corresponde ao comportamento geral da borda da Bacia Sedimentar do Paraná.

Essas formas típicas de um relevo de estrutura concordante horizontal ou sub-horizontal são observadas através da passagem das escarpas e testemunhos derivados do Planalto de Franca para os terrenos pré-cambrianos, onde são encontrados restos isolados de rochas sedimentares. Esse conjunto forma no terreno desníveis e patamares de tamanhos variados, que marcam contatos entre unidades litoestratigráficas e indicam alternância entre camadas ou variação de resistência à erosão entre elas caracterizando um relevo tipicamente tabuliforme.

O relevo reconhecido no compartimento-2 "Patamares da Canastra" possui um acamamento associado a camadas inclinadas, e por isso gera um padrão de relevo que varia de moderado a levemente assimétrico, conferido por cristas alinhadas sustentadas por quartzitos. Essas cristas alinhadas possuem uma forma aproximadamente tabular das camadas que possibilita perceber não só a inclinação dos estratos através da observação dos traços de contato entre as camadas, conferidos nas encostas e vertentes, como também a importância e resistência a erosão dos quartzitos, que preservaram dos processos erosivos feições imponentes como a Antiforma de Itaú e a Sinforma do Chapadão. No compartimento-3 "Planalto de Varginha" a disposição de seus litotipos verticalizados forma feições típicas de cristas retilíneas e alinhadas sustentadas pelos gnaisses (litologia mais resistente do comparti- 
mento). Essas feições dispõem de vertentes íngremes de ambos os lados e topos com formatos de cúspide ou arredondados que reforçam ainda mais a disposição de suas camadas inclinadas e o padrão de relevo simétrico, assim conferidas tanto na parte Norte da Serra da Fortaleza quanto na porção Leste da Serra do Chapadão.

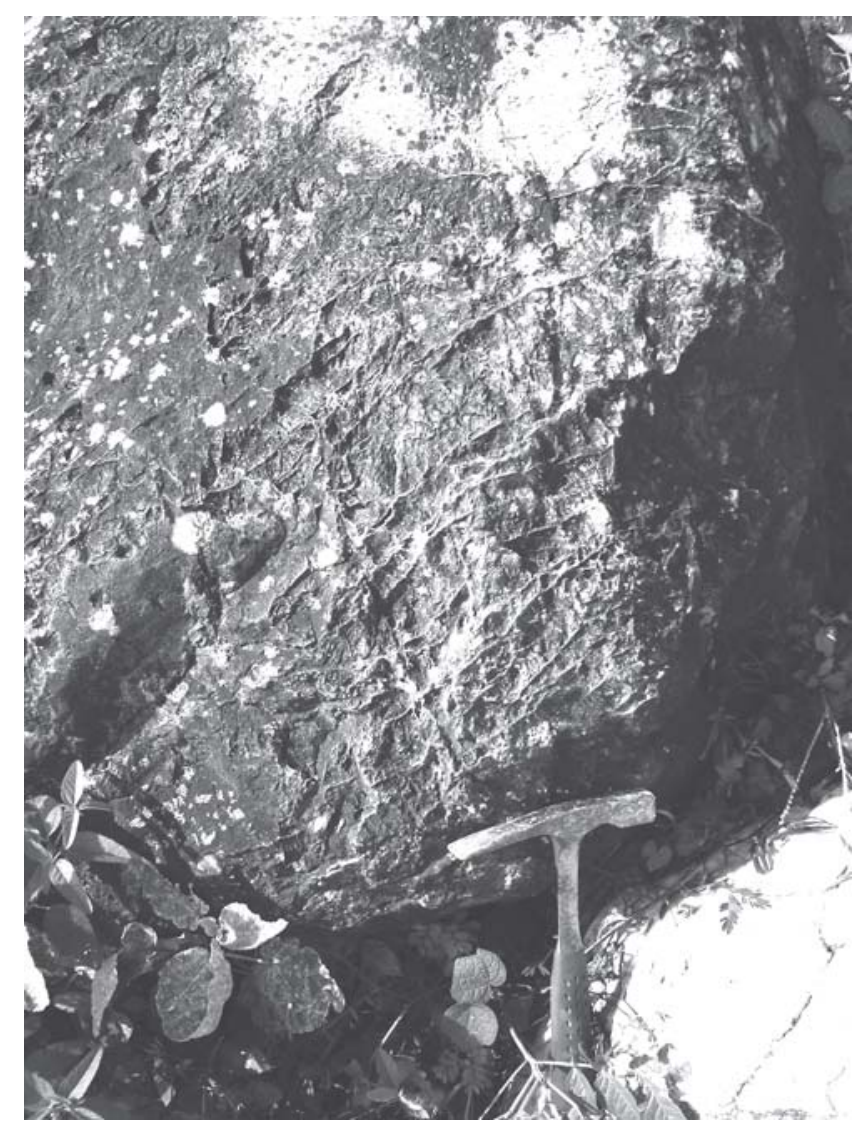

Figura 12 - Brecha silicosa aflorando na região da Serra do Agapito, NW da área de estudo.

Essas feições devem ser relacionadas ao histórico de erosão remontante que dissecou o relevo nas porções relacionadas ao Planalto de Franca, promoveu a formação dos escarpamentos cuestiformes e o desenvolvimento de patamares, peões e mesas em função de erosão dos sedimentos e das rochas basálticas. No compartimento central, ao romper a base das rochas sedimentares permocarboníferas do Grupo Itararé, o sistema erosivo denudou as estruturas das rochas pré-cambrianas, exibindo as estruturas presentes nas mesmas, decorrentes de processos colisionais ocorridos no final do Proterozóico (SIMÕES, 1995). A instalação do sistema de drenagem aproveitou zonas estruturadas e do domínio de rochas menos resistentes, principalmente no caso das zonas de rochas xistosas, onde foi possível promover as erosões mais profundas. Com isso, na porção leste, começaram a "perdurar", frente aos processos erosivos, as rochas mais resistentes, com destaque para os quartzitos, enquanto na porção oeste os basaltos e diabásios sustentaram o relevo.

Cabe ressaltar que estão presentes nas feições de relevo, nos padrões e anomalias de drenagens dos domínios os registros da atuação de eventos relacionados com o tectonismo da Zona de Falha de Cássia.

Percebe-se que estas feições mostram um controle estrutural do padrão de relevo e de drenagem. Indicam também a atuação de reativação ao longo de seus traços através da forte linearidade de cristas e das escarpas na região da Serra do Agapito e da Serra do Itambé e pela forte linearidade dos traços de drenagem onde é possível o reconhecimento de anomalias, zonas de confluência alinhadas e padrões que insinuam este controle tectônico. A reativação desta zona de falha, provavelmente relacionada a eventos neotectônicos é reforçada pela disposição destes sedimentos que são encontrados retrabalhados, deformados e falhados.

Desta forma, nota-se que para a área de estudo, a atuação de processos exógenos e endógenos contribuíram ativamente no modelado atual e na compartimentação geomorfológica da área estudada. Considerando que as atividades intempéricas modificaram e forneceram a identidade morfológica do relevo atual que foi controlado pelas litologias e estruturas presentes conferidos aos processos endógenos, que também podem ser reconhecidos pela reativação da Zona de Falha de Cássia e sua relação a um quadro neotectônico.

\section{Referências Bibliográficas}

ALMEIDA, F.F.M. Fundamentos geológicos do relevo paulista. São Paulo, USP-Instituto de Geografia/IGEOG, 1974. 110p. (Série teses e monografias, 14).

BISHOP, P. Drainage rearrangement by river capture, beheading and diversion. Progress in Physical Geography, Londres, v. 19, n. 4, p. 449-473,1995.

BURKE, K. \& GUNNELL, Y. The African Erosion Surface: A continental-scale synthesis of geomorphology tectonics, and environmental change over the past 180 million years. The geological society of America, Colorado, v.2, 66p. 2008.

BURBANK, D.W. \& ANDERSON, R.S. Tectonic Geomorphology. Malden: Blackwell Science, inc. 2001. 274 p.

CASSETI, V. Elementos de Geomorfologia GOIANIA: CEGRAF-UFG, 1994. 137 p.

CASTRO, J.C. Glaciações paleozóicas no Brasil. In: NETO, V.M.; BARTORELLI, A.; CARNEIRO, C.D.; BRITONEVES, B.B. (Coordenadores), Geologia do Continente Sul-Americano: evolução e obra de Fernando Flávio 
Marques de Almeida. São Paulo: Editora Beca, 2004, p. 151-162.

FIORI, A.P. Estratigrafia do Grupo Tubarão (Formação Aquidauana) na região sudoeste do estado de Minas Gerais. 1977. 86f. Dissertação (Mestrado em Mineralogia e Petrologia) - Instituto de Geociências, USP, São Paulo.

GONTIJO, A.H.F. Morfotectônica do médio vale do rio Paraíba do Sul: região da serra da Bocaina, estados de São Paulo e Rio de Janeiro. 1999. 259f. Tese (Doutorado em Geologia Regional) - Instituto de Geociências e Ciências Exatas, UNESP, Rio Claro.

IBGE. Carta topográfica de Cássia: Folha SF 23 V A VI 1. Rio de Janeiro: IBGE, ano. 1 mapa, color., $56 \mathrm{cmx} 78 \mathrm{~cm}$. Escala 1:50.000.

IBGE. Carta topográfica de São Sebastião do Paraíso: Folha SF 23 V A VI 3. Rio de Janeiro: IBGE, ano. 1 mapa, color, $56 \mathrm{~cm} \times 78 \mathrm{~cm}$. Escala 1:50.000.

KING, L.C.A. Geomorfologia do Brasil Oriental. Revista Brasileira de Geografia, v. 18, p. 147-265, 1956.

MORALES, N. Evolução Tectônica do Cinturão de Cisalhamento Campo do Meio na sua porção ocidental. 1993. 125f. 2.v. Tese (Doutorado em Geologia Regional) Instituto de Geociências e Ciências Exatas, UNESP, Rio Claro.

OLIVEIRA, M.A.F.; MORALES, N.; RODRIGUES, M.F.B., CARVALHO, S.G.; ZANARDO, A. Geologia das Quadriculas Cássia e São Sebastião do Paraíso, MG. In: SIMPÓSIO DE GEOLOGIA DE MINAS GERAIS, 2., 1983, Belo Horizonte. Atas... Belo Horizonte: SBG, p. 432-439.

PENTEADO, M.M. Gemorfologia do Setor Centro-Ocidental da Depressão Periférica Paulista. São Paulo, USP- Instituto de Geografia/IGEOG, 1976. 86p. (Série de Teses e Monografias, 22).

PERDONCINI, L.C. Mesozoic-Cenozoic evolution of diamantiferous province of Franca. Revista Brasileira de Geociências, São Paulo, v. 31, n. 4, p. 665-668, 2001.

PIRES, F. Análise paleoambiental e estratigráfica do subgrupo Itararé na região do médio Tiete, Estado de São Paulo. 2001. 113p. Tese (Doutorado em Geociências e Meio
Ambiente) - Instituto de Geociências e Ciências Exatas, UNESP, Rio Claro.

SAADI, A. Elementos de discussão da neotectônica brasileira. In: SIGEG, SEMANA DE ESTUDOS GEOLÓGICOS, 31, Belo Horizonte, Anais, 1-12. 1990.

SAADI, A. Ensaio sobre a morfotectônica de Minas Gerais. 1991. 285f. Tese (Professor Titular) - Instituto de Geociências, UFMG, Belo Horizonte.

SAADI, A. Neotectônica da Plataforma Brasileira: esboço e interpretação preliminares. Geonomos, Revista de Geociências da UFMG. Belo Horizonte. v.1, n.1, p.1-15, 1993.

SIMÕES, L.S.A. Evolução tectono-metamórfica da nappe de Passos, sudoeste de Minas Gerais. 1995. 149 f. Tese (Doutoramento em Mineralogia e Petrologia) - Instituto de Geociências, USP, São Paulo.

SOARES, P.C.; FIORI, A. P. Lógica e sistemática na análise e interpretação de fotografias aéreas em geologia. Notícias Geomorfológicas, Campinas, v. 16, n. 32, p. 71-104, 1976.

STEWART, I.S \& HANCOCK, P.L. 1994. Neotectonics. In: HANCOCK, P.L. (Ed.). Continental Deformation. Oxford, Pergamon Press. p. 370-409.

SUMMERFIELD, M.A. Global Geomorphology. An introduction to the study of landforms. Editora Longman Scientific \& Technical . 1991.537 p.

VALERIANO, C.M.; DARDENE, M.A.; FONSECA, M.A.; SIMÕES, L.S. A. \& SEER, H.J. A Evolução Tectônica da Faixa Brasília. In: MANTESSO-NETO, V.; BARTORELLI, A.; CARNEIRO, C.D.R.; BRITO-NEVES, B.B. (Coordenadores), Geologia do Continente Sul Americano: evolução da obra de Fernando Flávio Marques de Almeida. São Paulo: Beca, 2004 p. 575-592.

WERNICK, E., FIORI,A. P.,BETTENCOURT, J.S, CHOUDHURI, A.A. Tectônica Rígida do Ciclo Brasiliano e sua implicação na Estruturação da Borda Sul e Sudeste do Cráton do São Francisco: Tentativa de um Modelo Preliminar. In: SIMPÓSIO SOBRE O CRATON DO SÃO FRANCISCO E SUAS FAIXAS MARGINAIS, 1, 1979. Salvador,. Anais...Salvador: SME-BAISBG-BA, p.164-168. 